bacterium chelonae infection in a hospitalized patient. J Am

Acad Dermatol 2014;71:e248-e250.

4. Yoo JS, Huh JW, Kim MS, Jue MS, Choi KH, Park HJ.
Cutaneous atypical mycobacterial infection in a body scrubber (“Ddaemirri"). Korean J Dermatol 2017;55:156-157.

\title{
A Case of Recalcitrant Erythema Nodosum Associated with Pancreatic Cancer
}

\author{
In Soon Jung, Sook Jung Yun, Jee-Bum Lee, Seung-Chul Lee, Young Ho Won \\ Department of Dermatology, Chonnam National University Medical School, Gwangju, Korea
}

\section{Dear Editor:}

A 56-year-old female presented with erythematous nodules on arms and legs, which first appeared on legs two weeks prior (Fig. 1). The patient had not previously experienced similar symptoms. She had no specific medication, medical, or family history and showed no systemic symptoms. Routine blood examination showed no specific findings. Skin biopsy showed fibrous interlobular septum with widening and septal infiltrate by inflammatory cells, including histiocytes, lymphocytes, and eosinophils. Infiltrate extended to adjacent fat lobules near the septa. Von Kossa stain was negative (Fig. 2). Although the patient was administered pentoxyfylline, colchicine, zaltoprofen and prednisolone $(10 \mathrm{mg} /$ day), the number of lesions continued to increase (Fig. 1). Further investigations were conducted to identify the reason for treatment resistance. Laboratory tests showed an increase in lipase $(14,139 \mathrm{U} / \mathrm{L}), \alpha$-fetoprotein $(829.9 \mathrm{IU} / \mathrm{ml})$, and carbohydrate antigen 19-9 (86.08 $\mathrm{U} / \mathrm{ml}$ ). Abdominal computed tomography showed malignant pancreatic cancer with metastasis to the liver and kidneys. The prednisolone dose was increased to $40 \mathrm{mg} /$ day, but there was no improvement. She died of tumor lysis syndrome 5 days after diagnosis of malignancy
Erythema nodosum (EN) can be idiopathic or secondary to infection, medication, inflammatory disease, or malignancy ${ }^{1}$. Although majority of cases associated with malignancy have been reported in relation to hematologic malignancies ${ }^{2}$, there are rare reports of EN secondary to solid tumors, such as lung cancer, colon cancer, and parathyroid cancer. Cases associated with pancreatic cancer are especially rare $^{3,4}$. We were unable to find any reported cases of EN in pancreatic cancer patients in Korean literature. In the present case, the patient had no factors except pancreatic cancer that could have caused EN. Moreover, the patient developed EN at 56-year-old and showed no improvement in spite of over 2 months of appropriate treatment. There is no clear difference in clinicopathological features between idiopathic and paraneoplastic EN. It is difficult to distinguish between these two states by morphologic findings and distribution pattern. The most helpful clue is disease course and response to treatment. Paraneoplastic EN shows poor response to treatment and relapses more frequently than idiopathic EN. Chowaniec et al. ${ }^{1}$ reported that malignancy must be considered as a cause of EN in cases with clinical symptoms such as weight loss, age over 50 years and poor response to treatment. In pancreatic

\footnotetext{
Received March 13, 2019, Revised May 7, 2019, Accepted for publication June 1, 2019
}

Corresponding author: Young Ho Won, Department of Dermatology, Chonnam National University Medical School, 42 Jebong-ro, Dong-gu, Gwangju 61469, Korea. Tel: 82-62-220-6681, Fax: 82-62-222-4058, E-mail: yhwon@jnu.ac.kr ORCID: https://orcid.org/0000-0003-4640-4337

This is an Open Access article distributed under the terms of the Creative Commons Attribution Non-Commercial License (http://creativecommons.org/licenses/by-nc/4.0) which permits unrestricted non-commercial use, distribution, and reproduction in any medium, provided the original work is properly cited.

Copyright $($ The Korean Dermatological Association and The Korean Society for Investigative Dermatology 

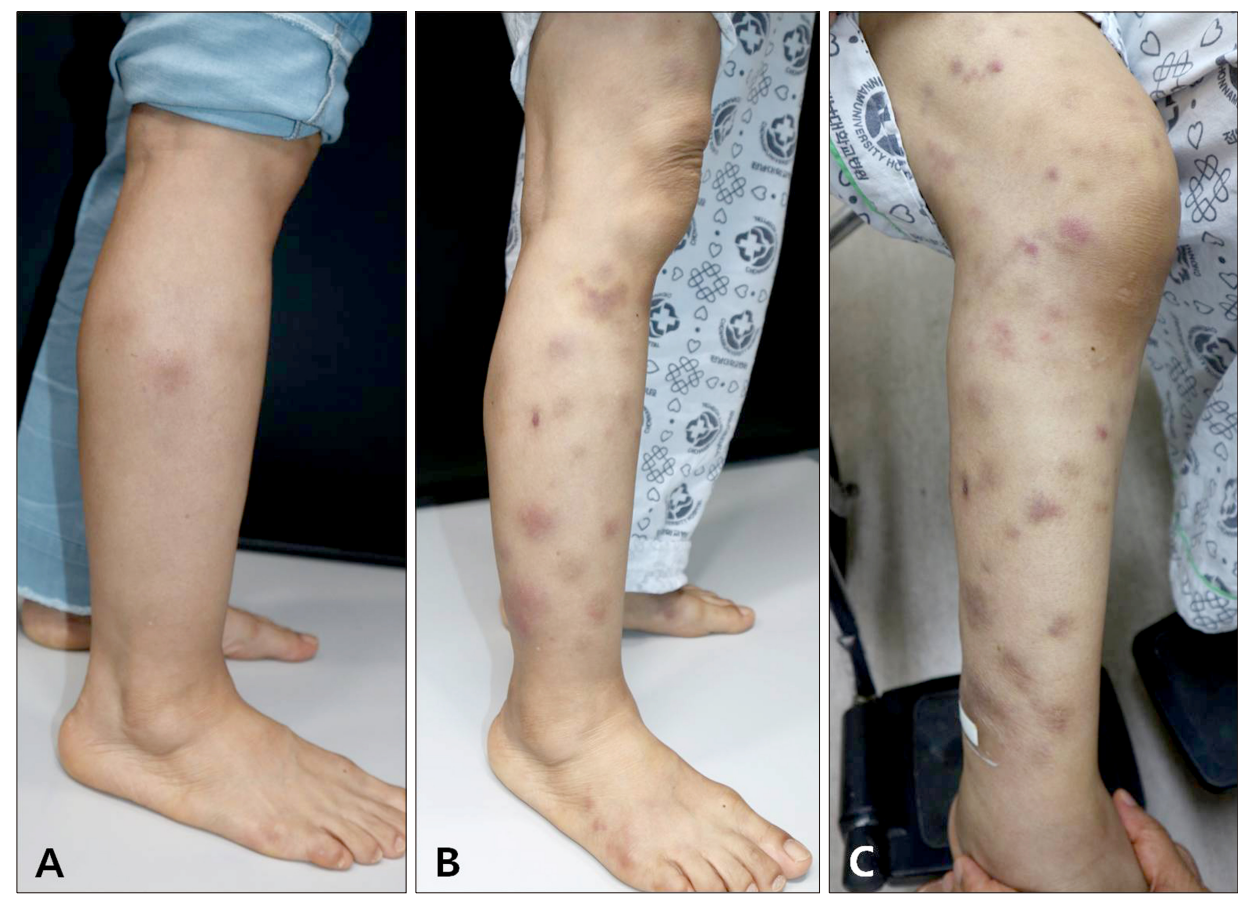

Fig. 1. Erythematous subcutaneous nodules on the right leg at first visit (A), 4 weeks (B), and 6 weeks later (C). The skin lesions aggravated despite intensive therapy including oral colchicines, analgesics, and oral steroid. We received the patient's consent form about publishing all photographic materials.
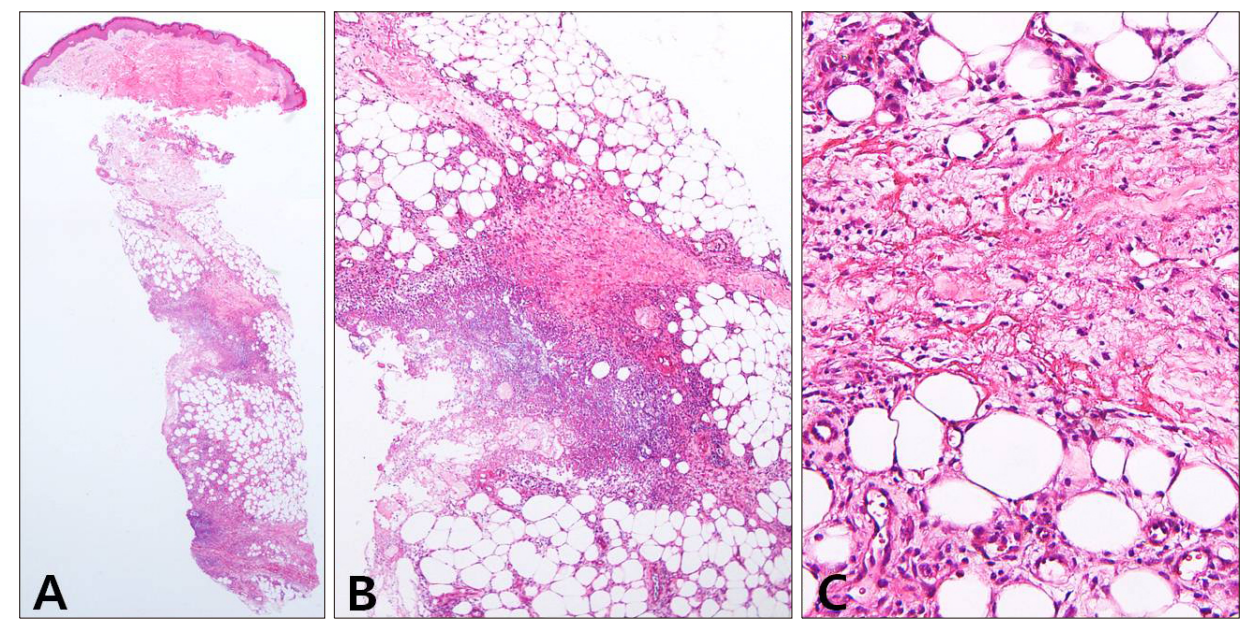

Fig. 2. Skin biopsy form leg nodule revealed fibrous interlobular septum with widening and septal infiltrate by inflammatory cells, including histiocytes, lymphocytes, and eosinophils. The infiltrate extends into adjacent fat lobules (H\&E: A, scanning view; $B, \times 100 ; C, \times 200)$.

cancer patients with panniculitis, it is important to differentiate between EN and pancreatic panniculitis. It is clinically similar to EN, with erythematous nodules mostly appearing on the legs ${ }^{5}$. However, it can be differentiated from EN histologically due to the presence of a lobular panniculitis pattern with ghost cells, which occur when adipose cells lose their nuclei due to calcium deposits, leaving only an outline. Von Kossa stain can be used to identify calcium deposits, which was negative in the present case.

We experienced a rare case of $\mathrm{EN}$ in a patient with pancreatic cancer, and we believe this is the first report in Korea. This case shows the importance of considering possibility of malignancy, including pancreatic cancer, in cas- es of EN that do not show improvement following treatment.

\section{CONFLICTS OF INTEREST}

The authors have nothing to disclose.

\section{ORCID}

In Soon Jung, https://orcid.org/0000-0002-0548-7159

Sook Jung Yun, https://orcid.org/0000-0003-4229-5831

Jee-Bum Lee, https://orcid.org/0000-0002-1477-4037

Seung-Chul Lee, https://orcid.org/0000-0002-4428-3837

Young Ho Won, https://orcid.org/0000-0003-4640-4337 


\section{REFERENCES}

1. Chowaniec M, Starba A, Wiland P. Erythema nodosum review of the literature. Reumatologia 2016;54:79-82.

2. Matsuoka LY. Neoplastic erythema nodosum. J Am Acad Dermatol 1995;32(2 Pt 2):361-363.

3. Virshup AM, Sliwinski AJ. Polyarthritis and subcutaneous nodules associated with carcinoma of the pancreas. Arthritis
Rheum 1973;16:388-392.

4. Durden FM, Variyam E, Chren MM. Fat necrosis with features of erythema nodosum in a patient with metastatic pancreatic carcinoma. Int J Dermatol 1996;35:39-41.

5. Arbeláez-Cortés A, Vanegas-García AL, Restrepo-Escobar M, Correa-Londoño LA, González-Naranjo LA. Polyarthritis and pancreatic panniculitis associated with pancreatic carcinoma: review of the literature. J Clin Rheumatol 2014;20:433-436.

\title{
Repigmentation of Eyebrow Leukotrichia in Segmental Vitiligo Treated with Suction Blister Epidermal Grafting Following Hair Plucking
}

\author{
Se Jin Oh, Cho Rok Kim ${ }^{1}$, Ji-Hye Park, Dong-Youn Lee, Dokyoung Yoon \\ Department of Dermatology, Samsung Medical Center, Sungkyunkwan University School of Medicine, ${ }^{1}$ Kye Dermatology Clinic, Seoul, Korea
}

\begin{abstract}
Dear Editor:
Vitiligo is generally classified into two clinical categories, nonsegmental vitiligo and segmental vitiligo (SV) ${ }^{1}$. SV on hairy areas such as the scalp and eyebrows is frequently associated with leukotrichia ${ }^{2}$. SV with overlying leukotrichia is refractory to conventional medical treatments because leukotrichia itself suggests a deficient melanocyte reservoir within the hair follicles ${ }^{1}$. Thus surgical management including epidermal grafting should be considered and preferred as an early intervention for the SV with leukotrichia, however only few literature showed improvement following surgical treatment. Herein, we present two cases of SV on the eyebrow successfully treated with suction blister epidermal grafting (SBEG) after hair plucking. An 11-year-old boy showed SV and leukotrichia on his left eyelid and forehead which had developed 8 months ago
\end{abstract}

(Fig. 1A). A 16-year-old girl had SV with leukotrichia on her right eyebrow and eyelid (Fig. 2A). Both cases did not respond to 6 months of conventional combination treatment including 308-nm excimer laser, topical steroid, and a calcineurin inhibitor. SBEG was performed under the consent of both the patients. Hairs of the eyebrow were pulled with forceps as a whole, including the hair follicle. Thigh skin was used as a donor for epidermal grafting. Vacuum suction was performed to donor sites at a pressure of 200 to $250 \mathrm{mmHg}$, and blisters formed after 2 hours. Epidermis on the recipient site was removed with defocusing, superpulsed mode $\mathrm{CO}_{2}$ laser. Subsequently, the roofs of the bullae were carefully excised and grafted. The recipient areas were almost completely pigmented and leukotrichia was significantly improved after $1 \sim 2$ years of clinical follow-up (Fig. 1B, 2B).

\footnotetext{
Received March 13, 2019, Revised May 9, 2019, Accepted for publication June 3, 2019
}

Corresponding author: Dong-Youn Lee, Department of Dermatology, Samsung Medical Center, Sungkyunkwan University School of Medicine, 81 Irwon-ro, Gangnam-gu, Seoul 06351, Korea. Tel: 82-2-3410-6578, Fax: 82-2-3410-3869, E-mail: dylee@skku.edu ORCID: https://orcid.org/0000-0003-0765-9812

This is an Open Access article distributed under the terms of the Creative Commons Attribution Non-Commercial License (http://creativecommons.org/licenses/by-nc/4.0) which permits unrestricted non-commercial use, distribution, and reproduction in any medium, provided the original work is properly cited.

Copyright (c) The Korean Dermatological Association and The Korean Society for Investigative Dermatology 